\title{
The socio-spatial patterns of heat stress exposure in Helsinki on two hot days of 2018 and 2019
}

\author{
Exposure to heat stress varies due to the large-scale weather pattern and local factors \\ such as the urban heat island effect, type of built environment, and-like in Helsinki- \\ impact of the sea and may vary significantly between heatwave events. Moreover, \\ the vulnerability characteristics of the exposed population play a notable role in the \\ health impacts. We present case studies of the socio-spatial exposure patterns to \\ heat stress in the Helsinki metropolitan area during two hot days of the 2018 and 2019 \\ heatwave events.
}

ATHANASIOS VOTSIS, REIJA RUUHELA, HILPPA GREGOW

Finnish Meteorological Institute

Heatwaves and urban resilience. Temperature extremes, floods, drought and water scarcity-along with impacts on human healthare indicated by the IPCC as the key climate change risks in urban areas (Revi et al. 2014). Addressing unequal exposure and vulnerability to temperature extremes across demographic groups has direct links to the UN's Sustainable Development Goals and the notion of systemic resilience. As the climatology of heatwaves is changing, necessitating the updating of warning systems and architectural or urban planning standards, information on the spatiotemporal behavior of heatwaves, interface with the built environment, and impacts on residents is becoming crucial. The urban heat island (UHI) effect may magnify the health impacts of heat stress in urban areas. In Helsinki, the mortality attributable to heatwaves can be about 2.5 times higher than in the surrounding, more rural area (Ruuhela et al. 2021). However, the intensity and spatial distribution of the UHI also

\begin{tabular}{|c|c|c|c|c|c|c|c|c|}
\hline \multirow[b]{2}{*}{ risk level } & \multicolumn{2}{|c|}{$\begin{array}{l}\text { \% POPULATION } \\
\text { EXPOSED }\end{array}$} & \multicolumn{2}{|c|}{$\begin{array}{c}\text { \% ELDERLY 75+ } \\
\text { EXPOSED }\end{array}$} & \multicolumn{2}{|c|}{$\begin{array}{c}\text { \% WORKPLACES } \\
\text { EXPOSED }\end{array}$} & \multicolumn{2}{|c|}{$\begin{array}{l}\text { \% DWELLINGS } \\
\text { EXPOSED }\end{array}$} \\
\hline & $\begin{array}{l}2 / 8 / \\
2018\end{array}$ & $\begin{array}{l}28 / 7 / \\
2019\end{array}$ & $\begin{array}{l}2 / 8 / \\
2018\end{array}$ & $\begin{array}{l}28 / 7 / \\
2019\end{array}$ & $\begin{array}{l}2 / 8 / \\
2018\end{array}$ & $\begin{array}{l}28 / 7 / \\
2019\end{array}$ & $\begin{array}{l}2 / 8 / \\
2018\end{array}$ & $\begin{array}{l}28 / 7 / \\
2019\end{array}$ \\
\hline -, green & 0.8 & 0.7 & 0.9 & 0.8 & 1.1 & 1.1 & 0.9 & 0.9 \\
\hline $\begin{array}{l}\text { hot, } \\
\text { yellow }\end{array}$ & 30.9 & 11.6 & 33.4 & 9.2 & 56.4 & 6.7 & 34.7 & 10.3 \\
\hline $\begin{array}{l}\text { very hot, } \\
\text { orange }\end{array}$ & 68.4 & 87.6 & 65.7 & 90.0 & 42.5 & 92.2 & 64.4 & 88.8 \\
\hline
\end{tabular}

TABLE 1: Key exposure and vulnerability indicators during the $2 / 8 / 2018$ and 28/7/2019 heatwaves.

vary depending on the synoptic situation, and in a coastal city like Helsinki, the impact of the sea is substantial. In these case studies of two hot days during heatwaves in 2018 and 2019 with different weather patterns we demonstrate the role of weather, specifically wind direction, on the spatial distribution of exposure to heat stress, and on the severity of the exposure according to selected factors affecting vulnerability of the population.
Spatial patterns from MEPS gridded operational forecast data. A hot day in Finland is defined as one with $\mathrm{T}_{\text {dmax }}>=25.1^{\circ} \mathrm{C}$. A heatwave occurs if this lasts for at least three days, although no official definition exists. Two recent heatwave events in a large Finnish urban region, in the Helsinki metropolitan area, occurred in 2018 and 2019. To benefit from a continuous spatial coverage and account for the non-trivial interaction between 

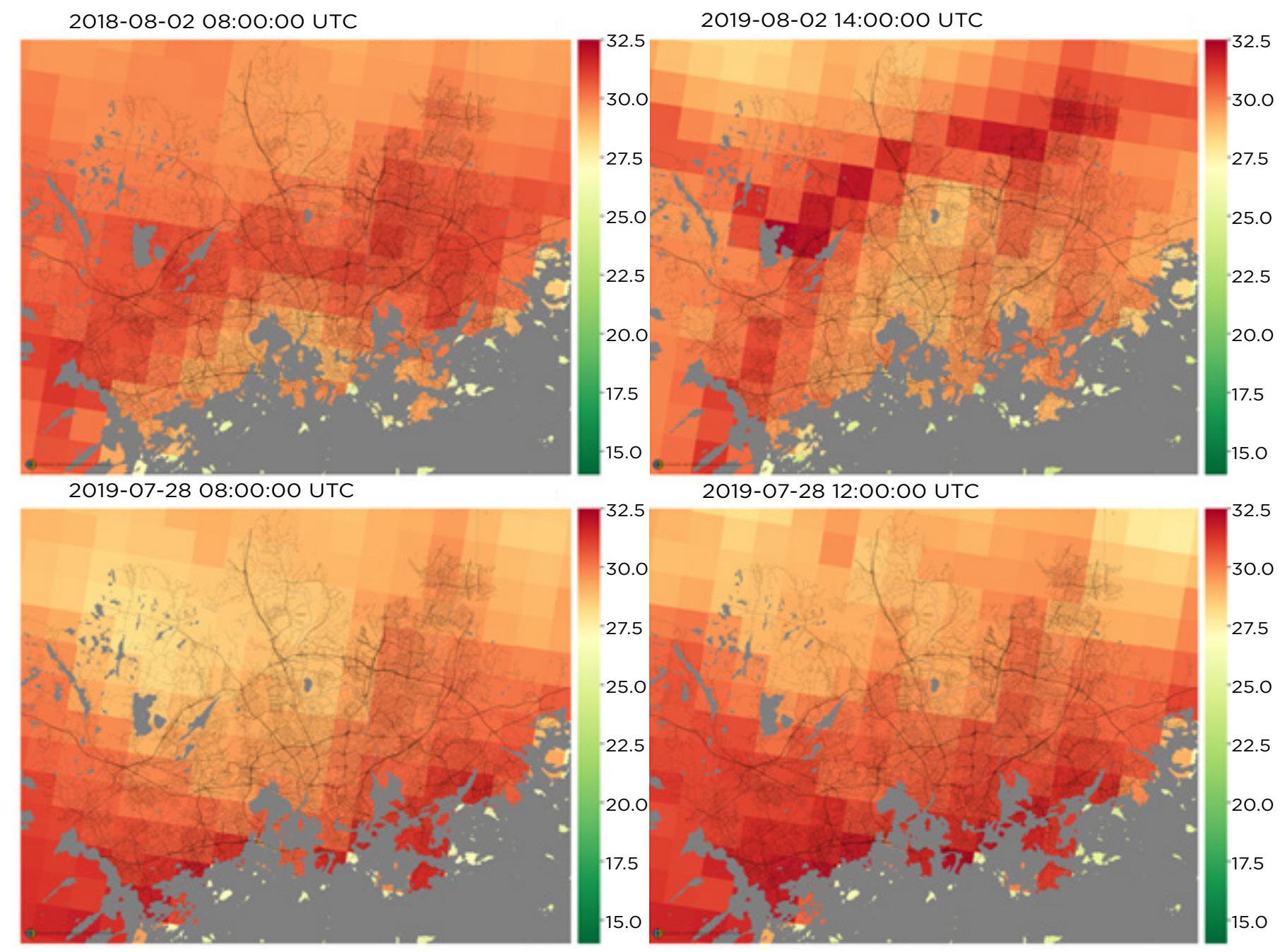

FIG 1: Morning (left) and afternoon (right) static snapshots of apparent temperature $\left({ }^{\circ} \mathrm{C}\right.$ ) in the Finnish capital region on $2 / 8 / 2018$ (top) and 28/7/2019 (bottom).

meteorology and the built environment, we retrieved data from the MetCoOp Ensemble Prediction System (MEPS), an hourly weather forecast product based on HARMONIE-AROME that covers the Nordic Region at a $2.5 \mathrm{~km}$ horizontal resolution (Müller et al. 2017). A SURFEX land surface model is coupled to this operational forecast of the Finnish Meteorological Institute, including information on surface physiographic characteristics such as land use, vegetation types, and urban morphology. From the forecast data we produced a gridded representation of the spatiotemporal variation of thermal comfort conditions on two hot days during the heatwaves using apparent temperature (AT) (Steadman 1994) based on air temperature and relative humidity at $2 \mathrm{~m}$, and wind speed at 10 m. Fig. 1 presents the progression of AT during the hottest days of the two heatwaves: $2 / 8 / 2018$ and 28/7/2019.

These animations show how the direction of the airstream affected the spatial distribution of thermal exposure. During the hot day in 2018 mainly southwesterly wind from the sea prevailed.
This wind direction led to cooler conditions on the shoreline than inland. In addition, the relatively narrow band of the highest thermal exposure north of the most densely built urban area suggests that the southwesterly winds advected warmer air from the area of the strongest UHI. During the hot day in 2019 northerly wind from inland prevailed. This led to a nearly opposite pattern in the spatial distribution of thermal exposure. In this case, the cooling effect of the sea was lacking, and the shoreline was warmer than the inland during both day and night. 
The highest thermal exposure on the shoreline suggests in this case that the northerly wind advected warmer air from the densely built areas.

Exposure and social vulnerability. Exposure to heat stress in Helsinki varies due to several factors, notably the urban heat island effect, type of built environment, weather pattern and impact of the sea. An additional factor is the population vulnerability during heatwaves. As an initial overview, we provide in Table 1 an overlay of the gridded socioeconomic data by Statistics Finland with the spatiotemporal distribution of the national heat warning risk levels, namely 'hot (yellow)' (if $\mathrm{T}_{\text {dmax }}>=27$ and $\mathrm{T}_{\text {dmean }}>=20^{\circ} \mathrm{C}$ ) and 'very hot (orange)' (if $\mathrm{T}_{\mathrm{dmax}}>=$ 30 and $\mathrm{T}_{\text {dmean }}>=24^{\circ} \mathrm{C}$ ). More specifically, the MEPS gridded data enable the calculation of the risk levels in a geographically resolved manner, making it possible to understand the exposure patterns of the population, infrastructure, and of different vulnerability groups in better detail than with city-wide aggregate data.

The selected indicators demonstrate that the exposure of the population to different levels of heat stress may vary substantially in Helsinki-in addition to meteorological factors and characteristics of the built environment-due to the spatial distribution of population and their daily activities. These first case studies on the spatial distribution of exposure to heat stress during heatwaves in Helsinki reveal the need for further studies on vulnerability factors that would benefit health impact studies and urban planning. The use of forecast data from the operational weather prediction model suggests that there is also potential for targeted, tailored forecasts for urban areas to prepare for heatwaves. Lastly, meteorological data from a longer time horizon and the addition of mortality, morbidity and productivity data will enable the detection of possible location-specific human adaptation or acclimatization trends in the population, thus making a further step in understanding adaptation pathways and sustainability transitions in urban areas.

Acknowledgements. The study contributes to SmartLand/SLUPSU project (Smart Land use policy for sustainable urbanization) funded by the Finnish Strategic Research Program (decision No. 327803), URCLIM project (Advance on Urban Climate Services) funded by the EU Era4CS program (grant No. 690462), CHAMPS project (Climate change and Health: Adapting to Mental, Physical and Societal challenges) funded by the Academy of Finland (decision No. 329225), and ACCC (Atmosphere and Climate Competence Center) Flagship project funded by the Academy of Finland (decision No. 337549e). We thank Herman Böök and Carl Fortelius for their support and guidance.

Müller, M., et al., 2017: AROME - MetCoOp: A Nordic convective scale operational weather prediction model, Weather \& Forecasting, https://doi.org/10.1175/WAF-D-16-0099.1.

Revi, A., et al., 2014: Urban areas, in Climate Change 2014: Impacts, Adaptation, and Vulnerability. Part A: Global and Sectoral Aspects, Cambridge University Press, 535-612.

Ruuhela, R., et al., 2021: Temperature-related mortality in Helsinki compared to its surrounding region over two decades, with special emphasis on intensive heatwaves, Atmosphere, 12(46), https://doi.org/10.3390/atmos12010046.

Steadman, R. G., 1994: Norms of apparent temperature in Australia, Aust. Met. Mag., 43, 1-16. 